\title{
Health System Response to COVID-19 Epidemic in India
}

\author{
Prema Ramachandran ${ }^{1} \quad$ Krishnamurthy Kalaivani ${ }^{1}$ \\ ${ }^{1}$ Nutrition Foundation of India

\begin{abstract}
Address for correspondence Prema Ramachandran, Nutrition Foundation of India, C 13 Qutab Institutional Area, New Delhi 110016, India (e-mail: f1prema@gmail.com).
\end{abstract}

Ann Natl Acad Med Sci (India):2020;2:67-76

\begin{abstract}
The coronavirus disease 2019 (COVID-19) epidemic, detected first in China in December 2019, is now rapidly spreading across the world. India responded by drawing up National Containment Plan for COVID-19 that envisaged screening of people for COVID-19 for early detection of infection, providing community, primary health care-centered management for those with mild infection, tertiary care for those with severe infection, and health education to the population to reduce person-to-person transmission of infection. To minimize the spread of infection from other countries, all travelers were screened and quarantined; in the third week of March, India imposed ban on all international travel. To prevent person-to-person spread, congregation of people for commercial, educational, entertainment, sports, religious, and other social activities was banned. To minimize intracity, interstate, and urban rural spread, India imposed nationwide lockdown on 25th March 2020. The lockdown flattened the epidemic curve and provided needed time for the country to reorganize the health system, so that it can provide needed care for the increasing number of COVID-19 patients at all levels of health care. National guidelines for screening of people for severe acute respiratory syndrome-coronavirus- 2 infection, quarantine, and home isolation and care of infected people were drawn up and implemented. Health education on methods by which person-to-person transmission of infection can be minimized has been provided using all media of communication. Global comparison shows that currently India has low infection rates, low fatality rates per 1,00,000, and high recov-

Keywords

- COVID-19 epidemic

- health system response

- health education

- national guidelines

- home care

- hospital-based care ery rates. There are ongoing research studies to document the course and outcome of COVID-19 in India. Clinical trials of potential drugs for treatment of severe infections and vaccines for preventing infection in the high-risk groups are underway. A COVID-19 disease surveillance program is underway to track the infection rates and bring appropriate midcourse corrections in interventions. In the coming months, the people and health system will not only have to evolve a sustainable strategy to provide needed care for COVID-19 cases but also ensure that all other health care programs are implemented and patients with other illnesses get optimal care too.
\end{abstract}

\section{Introduction}

On December 31, 2019, China reported to the World Health Organization (WHO) that there was a pneumonia outbreak in Wuhan caused by a novel coronavirus as required under the International Health Regulation (IHR) 20053. The virus was named severe acute respiratory syndrome-coronavirus-2
"SARS-CoV-2" and the disease it caused was given the term "coronavirus disease 2019" (abbreviated to "COVID-19"). ${ }^{1}$ The globalized world across which millions of people travel every day, coupled with the highly contagious nature of the virus led to the rapid spread of COVID-19 across all countries in the world. Based on the speed and scale of transmission of 
SARS-CoV-2 reported from several countries across the globe, COVID-19 was declared a pandemic on March 11, 2020. ${ }^{1}$

India responded to COVID-19 pandemic with commendable speed and drew up the Containment Plan for Novel Coronavirus Disease 2019.2 The plan focused on screening people for early detection of SARS-CoV-2 infection, providing community-based primary health care-centered care for those with mild infection, tertiary care for those with severe infection, and health education to the population to reduce person-to-person transmission of infection.

In order to minimize spread of infection from other countries, in the phase 2 of the pandemic, India screened and quarantined all international travelers; later India imposed ban on all international travel. Congregation of people for commercial, educational, entertainment, sports, religious, and other social activities was banned to prevent person-to-person spread.

India imposed nationwide lockdown on March 25, 2020 to minimize intracity, interstate, and urban-rural spread. The pre-emptive lockdown flattened the epidemic curve in the initial months. The lockdown also provided needed time for the country to reorganize the health system so that the needed care for increasing number of COVID-19 patients can be provided at all levels of health care.

There is wide variation in the magnitude and severity of the infection and case fatality rates across countries ${ }^{1}$ and within states in large countries like India. ${ }^{2}$ Global comparison shows that India has low infection rates, high recovery rates, and low fatality rates. The present article reviews the response of health system and the people during the initial three months of the COVID-19 epidemic in India. Lessons learnt during implementation of interventions during the initial phase to the vast varied population, accessing health care under diverse settings, can help in bringing about midcourse correction in the public health response to this epidemic and improve the health outcomes.

\section{Perspective}

Earth is the home of a vast number of living organisms. Viruses have been inhabitants of the earth for millions of years. Humans are relatively late-comers but within a short period have brought about massive alterations in atmospheric, geologic, hydrologic, biospheric, and other earth systems. Earth's most recent geologic time period has been defined as Anthropocene period in recognition of the changes in the global environment brought about by human beings. One of the consequences of changes in ecology brought about by humans is a threat to the survival of viruses. When challenged by fall in number of animal hosts because of loss of their habitats, viruses try to survive by infecting abundantly available humans who are in close contact with the animals. It is estimated that there are $\sim 1.7$ million viral species circulating among wildlife and 50\% of these have the potential to cause zoonotic diseases in human beings. In the first two decades of this century, Ebola and Nipah viruses have caused relatively localized epidemics; severe acute respiratory syndrome (SARS-CoV), Middle East respiratory syndrome coronavirus, avian flu, and HINI flu were the more widespread but less lethal pandemics. Viewed in this perspective, the SARS-CoV-2 pandemic is one more of the zoonotic viral epidemic that will continue to occur at unpredictable time and place.

Following the SARS epidemic, IHR ${ }^{3}$ was revised to "provide a public health response to the international spread of disease in ways that are commensurate with and restricted to public health risks, and which avoid unnecessary interference with international traffic and trade." World Health Assembly approved IHR in May 2005. Subsequently all countries prepared National Pandemic Preparedness Plans that provided the frame work for evolving containment and control strategy for any future epidemics.

The already overstretched health systems providing preventive, promotive, curative, and rehabilitative services to the population cannot invest major proportion of their resources in maintaining a state of perpetual pandemic preparedness. The thrust of efforts was therefore on capacity building within the health system for early detection and effective response to epidemics as and when they arise. ${ }^{3}$ The capacity building included strengthening of the:

- Disease surveillance networks aimed at early detection of newer infections.

- Epidemiology networks enabling rapid documentation of the natural course and outcome of the disease.

- Research laboratories to rapidly develop diagnostic test for early detection of infection.

- Hospitals to provide care to mitigate morbidity and mortality.

- Public health system to evolve and implement interventions aimed at reducing the magnitude and severity of the epidemic.

- Communication system to inform the people and enable their active participation in the interventions.

It was envisaged that in the initial phases of the epidemic the health system will reorganize existing infrastructure and manpower to cope with the caseload by curtailing the routine follow-up care and elective procedures. Once the peak of the epidemic curve is reached, the focus will shift to sustaining the services for the new infection and progressively restoring the services under the national health programs, care of patients with other illnesses, and elective intervention procedure. This process of health system's response to COVID19 will continue until such time that the management of the new infection becomes one of the ongoing health programs.

\section{Evolution of COVID-19 Pandemic}

On December 31, 2019, China reported to the WHO that there was a pneumonia outbreak in Wuhan caused by a novel coronavirus as required under the IHR 2005. ${ }^{3}$ The virus was named "SARS-CoV-2" and the disease it caused was given the term "coronavirus disease 2019" (abbreviated to "COVID-19"). ${ }^{3}$ The globalized world across which millions of people travel every day, coupled with the highly contagious nature of the virus, led to the rapid spread of COVID-19 across all countries 
of the world. In December 2019, the SARS-CoV-2 spread from one city Wuhan to the entire Hubei province. January 2020 saw the spread of infection across China and to other countries. On January 30, 2020, COVID-19 was declared by the WHO as a "public health emergency of international concern" (PHEIC).

Based on the speed and scale of transmission SARS-CoV-2 reported from several countries across the globe, COVID-19 was declared a pandemic on March 11,2020. ${ }^{3}$

The WHO has defined four stages of the COVID-19 pandemic: ${ }^{3}$

Stage 1: There is no infection in the country.

Stage 2: Travelers bring the virus into the country and transmit it to people they come in contact with, usually friends and family.

Stage 3: People without travel history or known contact with an infected person get infected.

Stage 4: There are many major clusters of infection all over the country.

As the pandemic progresses, countries move from one to the next phase of transmission ( - Fig. 1). Irrespective of the phases of the epidemic, the objectives of public health response to COVID-19 are to:

- Prevent outbreaks, delay spread, and slow down transmission.

- Provide optimal care for all patients, ranging from asymptomatic infected people, to those with mild, moderate, and serious illness.

- Minimize the impact of the epidemic on health systems, ongoing other health programs, and essential health care.

\section{COVID-19 in China}

In the initial phase of the pandemic almost all the data on COVID-19 were generated in China. All available evidence suggests that SARS-CoV-2 has a natural animal origin and probably has its ecological reservoir in bats. The genome of the SARS-CoV-2 was sequenced first in China. This step paved the way for manufacture and use of tests for the diagnosis of SARS-CoV-2. Data from China showed that SARS-CoV-2 was genetically related to the coronavirus that caused the outbreak of SARS in 2003, but SARS was much less infectious but more deadly than COVID-19.
In an attempt to limit the exponential increase in the number of infected people, China:

- restricted the congregation of people for social, economic, educational, entertainment, or trade purposes.

- banned crowding especially in closed environment such as malls and theaters.

- closed schools and colleges.

Despite this, the spread of COVID-19 across the other provinces in China continued (Stage 3 of the COVID spread). China imposed and implemented a strict lockdown to limit Stage 4 of community transmission. After 2 months, China reported flattening of the epidemic curve; the lockdown was relaxed in a phased manner enabling resumption of agricultural, industrial, and economic activities. ${ }^{3}$

\section{Health Systems Response to COVID-19 Epidemic in India}

The first three confirmed COVID-19 cases in India were students who returned to Kerala from Wuhan. ${ }^{3}$ The state health minister announced that "children" returning from China will be quarantined at home and tested. When they tested positive, they and their families were kept under home quarantine and provided essential goods and services at home. All the three recovered. ${ }^{5}$ This experience set the tone and tenor of response to COVID-19 in Kerala. The clear guidelines and transparent handling of the initial cases and past experience of the state in successfully tackling epidemic of Nipah virus gave both health system and the aware literate population confidence that they can cope with the relatively milder COVID-19 epidemic and laid the foundation for the people-centered primary health care approach to the management of COVID-19 epidemic. ${ }^{5}$

\section{Screening of Travelers}

In the period January 31st to mid-March 2020, all the detected COVID -19 cases were people coming to India from COVID-19 affected countries and their contacts in India (Stage 2 of COVID-19 pandemic). In an attempt to reduce spread of infection, Government of India (GOI) put out an advisory against nonessential travel to China. Students stranded in

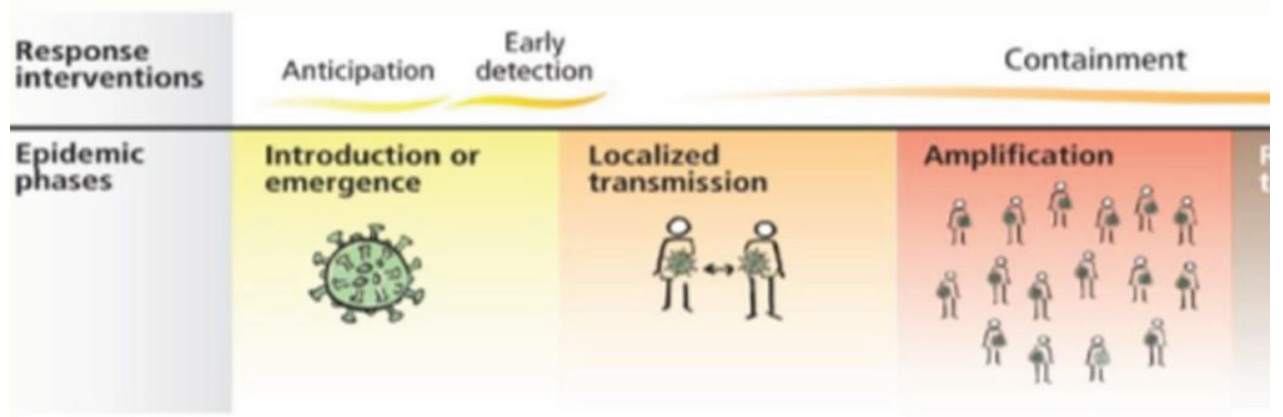

Fig. 1 Phases of the epidemic and responses. 
Wuhan were brought back to India by special flights, quarantined and tested. Those who tested negative were allowed to travel to their home. They were kept under home surveillance. If as and when they developed any respiratory symptoms, they were tested for COVID-19. ${ }^{3}$

During February 2020, the screening of incoming passengers in airports for fever was initiated: initially passengers from COVID-19 affected countries were screened, then all passengers coming to India were screened for fever. Those with symptoms were quarantined and tested for infection. A review of the experience in March 2020 showed that screening of people for fever is not an effective method of screening for COVID-19. ${ }^{3}$ The long wait for test results (screening and confirmatory testing) was a matter of concern and so the number of laboratories equipped to undertake testing for virus were increased and testing of people with symptoms was speeded up. Till March 4th 2020, 5,89,000 people had been screened at airports and over 1 million were screened at borders with Nepal. Around 27,000 were placed on quarantine at home and were followed up. ${ }^{3}$

During March, a steady stream of travelers (Indian and foreigners from different countries) was screened on arrival in the airports and symptomatic people were referred to health facilities; ${ }^{6}$ asymptomatic people were quarantined at home. ${ }^{7}$ If they were found positive, they and their families were quarantined at home for further 15 days. The contacts of people who had traveled to different places in India were traced and quarantined at home. Since they all were allowed to stay in their own homes during the quarantine period, compliance was good. All quarantined people and their contacts were followed up by the health staff and provided with needed advice; if any one developed symptoms of COVID-19, they were given symptomatic treatment and supportive care at home. They were advised to contact health staff (mobile phones, helpline numbers) if they developed high fever, difficulty in breathing. Those who developed these symptoms were admitted in the hospital. ${ }^{8}$

Despite such liberal measures, some of the travelers broke the quarantine and traveled without informing the health surveillance team. Their contacts during travel and in the places they visited were tested and several positive cases were detected. ${ }^{3}$ This led to more stringent measures to ensure compliance with quarantine. ${ }^{8,9}$ Quarantine facilities were established initially in Army establishments and subsequently in sports stadia. The quarantine and care facilities developed in trains ${ }^{10}$ (they are mobile can be taken wherever needed) and stadiums (they are empty as sports activities are not there) meant to accommodate $3,20,000$ people were kept fully functional but occupancy rates were low. ${ }^{3}$

\section{Lockdown 1.0, 2.0, and 3.0}

On March 11, 2020, the COVID-19 outbreak was declared an epidemic in India and provisions of the Epidemic Diseases Act, 1897, was been invoked; congregation of people for commercial, educational, entertainment, sports, religious, and other social activities was banned; all schools and colleges were closed. By the third week of March 2020, COVID-19 cases were reported from almost all states in India. Most of the cases were from urban areas; this was perhaps due to the differences in population density, as well as availability and access to testing facilities. India observed a 14-hour voluntary public curfew on 22nd March 2020, to test feasibility of a lockdown to prevent rapid spread of COVID-19 between states, districts, urban and rural areas, and between different areas in the densely populated cities.

Commencing on March 24, a nationwide lockdown for 21 days was ordered, affecting the entire 1.3 billion population of India. ${ }^{11}$ This was followed by Lockdown 2.0; Lockdown 3.0 and Lockdown 4.0 which is slated to end on May 31, 2020. All international, national, and interstate passenger transport (air, rail, bus, and car) were banned but transport of essential supplies and goods was allowed. In addition to trucks, railways rakes unutilized because of the industrial shutdown were used for transport of food, drugs, and other essential supplies. By and large essential goods and services were available across the country, though there were quality, variety, quantity, and cost-related issues.

\section{Guidelines for Testing for SARS-CoV-2}

Initially testing was mainly done for travelers from countries with COVID-19, their household, and other contacts. ${ }^{11}$ With the increasing number of testing institutions and availability of test kits, respiratory symptomatics seeking health care and contacts and household people of confirmed cases were tested. ${ }^{12}$ Indian Council of Medical Research (ICMR) guidelines ${ }^{13}$ recommend screening for SARS-CoV-2 in:

- All asymptomatic individuals who have undertaken international travel in the last 14 days.

- All symptomatic direct and high-risk contacts of a confirmed case (test once between day 5 and day 14 of coming in contact).

- Asymptomatic people in hotspots/clusters, (defined by Ministry of Health and Family Welfare [MoHFW]), large migrations/gatherings/evacuee centers.

- All symptomatics (fever, cough, sore throat, runny nose).

- All symptomatic contacts confirmed cases.

- All symptomatic health care workers.

- All patients with severe acute respiratory illness.

Testing of cases has been ramped up over the last month. Till May 13, 2020 a total of 18,54,250 samples have been tested. As compared with other countries, the positivity rates are relatively low. ICMR has initiated sentinel surveillance for assessing magnitude of the SARS-CoV-2 infection across the country. ${ }^{14}$ In the coming months, large-scale screening of population groups across states, facility-based district level surveillance, ${ }^{15}$ and sentinel surveillance ${ }^{14}$ will provide useful data to assess the prevalence of infection and the impact of ongoing interventions. 


\section{Providing Health Care to People Infected with SARS-CoV-2}

All infected people are asymptomatic immediately after infection; they can, however, transmit the infection even at this stage. Incubation period for COVID-19 is around 5 days (range: 1-14 days). Many infected people remain asymptomatic and eliminate the virus in about a month. Illness due to COVID-19 infection is generally mild, especially in children and young healthy adults. The most common symptoms of COVID-19 are fever, tiredness, and dry cough. Some patients may have aches and pains, nasal congestion, runny nose, sore throat, or diarrhea. About one out of every six patients with COVID-19 develop high fever and difficulty in breathing; they require hospitalization. There is as yet no specific antiviral drug to prevent or treat COVID-19. There is no evidence that hydroxyl-chloroquine can prevent or modify the course and outcome of COVID-19; it is being given on an empirical basis under careful medical supervision, as a prophylactic to health workers providing care to COVID-19 patients. Currently, there is no vaccine for the prevention of COVID-19. Clinical trials on potential drugs to treat severe infections and vaccine that could be useful to prevent infection in high risk individuals are underway and may come up with useful products within the next 12 months.

\section{Home Care for Asymptomatic Patients and Those with Mild IIIness}

Most patients with mild illness do not require hospitalization; they respond readily to symptomatic treatment (paracetamol for fever and body ache; antihistaminic for runny nose, and cough syrups for cough; adequate hydration and balanced diet with larger serving of vegetables and fruits). ${ }^{16}$ The family will be under home isolation for 2 weeks; they can provide comfort and care for infected patients under home quarantine. One of the major advantages of the home isolation and care of infected patients is that they are comfortable at home recover within a week or 10 days; they do not face psychological problems of being alone in a hospital. Guidelines for home management of asymptomatic and mildly symptomatic infected patients have been drawn up and are available in the website of MoHFW and the National Centre for Disease Control. ${ }^{16}$ The infected person and the family will be followed up by the health system personnel, provided the needed advice and care.

Testing of the family contacts will be done and if the family members are found to be infected, the home isolation period will be appropriately increased. The administration will ensure that all the goods and services needed by the family are provided at their doorstep, so that home isolation does not lead to any hardship in terms of accessing essential goods and services.

\section{Prevention of Intrafamily Infections during Home Care}

Infected patients (both symptomatic and asymptomatic) transmit the virus readily to others - when they speak, when they cough (droplet infection), or dry their nose and touch surfaces (surface contamination). All infected patients, therefore, should wear a multilayer cloth mask, observe respiratory etiquette, and wash their hand as and when they touch their face, nose or mouth. ${ }^{16}$ Family members who provide care should wear a mask, stay about a meter from the infected person, wash hands with soap and water as and when they touch the surfaces handled by the infected person. ${ }^{16}$

\section{Hospitalization and Care}

About 5\% of infected patients develop persistent high fever and/or breathlessness and require hospitalization. ${ }^{17}$ National Guidelines for screening symptomatic patients in hospital have been drawn up. ${ }^{18}$ Guidelines for the management of infected person in hospitals have been drawn up and are available in the website of MoHFW and the National Centre for Disease Control. ${ }^{17}$ Older people, and those with underlying medical problems like high blood pressure, heart problems, or diabetes, are more likely to develop serious illness. ${ }^{19}$ For the duration of the pandemic, GOI has designated some hospitals as COVID-19 centers. All hospitals have earmarked adequate proportion of their beds for COVID patients. ${ }^{20}$ So far the beds, including intensive care unit (ICU) beds allocated for COVID patients, have not been fully occupied. Discharge policy guidelines have been developed for hospitalized patients. ${ }^{21}$ Guidelines for disposal of hospital waste from wards where COVID-19 patients are receiving treatment have been developed. ${ }^{22}$ All hospitals continue to provide outpatient and inpatient care for the treatment of patients with other illnesses in areas away from the COVID-19 earmarked areas. ${ }^{23}$ This is to prevent cross-infection to the general hospital population and to ensure that medical care to non-COVID-19 patients is not compromised. Health care providers are provided with personal protection equipment to minimize the risk of infection while providing health care; ${ }^{23}$ however, some health care professionals do develop infection. Adequate provisions have been made to provide required care for these patients.

Management of acute severe respiratory distress in COVID-19 patients requires intensive care and the attending physicians should provide personalized care. There have been reports that aggressive management in ICUs and use of ventilators may not be associated with higher recovery rates. ${ }^{24}$ Efforts should be made to proactively reassure patients and provide prognostic information to the relatives.

\section{Health Education to Reduce Spread of Infection}

SARS-CoV-2 spreads through airborne respiratory droplets when an infected person coughs, sneezes, or speaks. Person close by gets infected by inhaling the virus containing droplets or by touching objects and surfaces contaminated with droplets containing the virus and later touching their nose or mouth. All people entering public places should take essential personal precautions to reduce risk of infection because it is not possible to know who is infected and 
who is not. Measures to reduce risk of infection include physical distancing, mask wearing, and hand washing after touching potentially infected surfaces in public places. ${ }^{25}$

\section{Physical Distancing}

One of the most important methods for reducing the risk of infection is staying away from any potentially infected patients. Global and Indian guidelines have empirically recommended that the minimum distance should be one meter. People should avoid going to crowded places and attending congregations to reduce risk of this airborne infection. ${ }^{25}$

\section{Wearing of Masks}

A multilayer cotton mask offers some protection to the wearer from droplets of infectious material emitted during coughing/sneezing/talking by an infected person and can be comfortably worn though the summer and monsoon..$^{26,27}$ To be effective the mask should cover the nose and mouth, be reasonably fitting and should be kept in place. Masks should be removed at least once in 6 hours or when they become moist with secretions or sweat. They should be washed well with soap and water and thoroughly dried before reuse. Masks have to be used by:

- quarantined people and people with respiratory symptoms to reduce the amount of potentially infected droplets reaching the environment and infecting others.

- those providing care to quarantined people and home care for infected patients have to wear similar mask to reduce the risk of their inhaling the infected droplets.

In the current phase of the epidemic, the use of these masks has been made mandatory whenever anyone leaves home and goes into a public place. This reduces risk of infection in two ways: less droplets from respiratory tract of those who are infected will reach others; those who are uninfected will inhale less of the contaminated droplets.

\section{Respiratory Etiquette}

It is well recognized that cough, runny nose, and fever are the most common symptoms of COVID-19; but not all respiratory infections are due to COVID-19. Since it may not be possible to test every person with mild respiratory symptoms for COVID-19, it is recommended that all people with mild respiratory symptoms should stay at home; they should practice respiratory etiquette of covering nose and mouth during sneezing and coughing to prevent spread of droplet infection to the family members. Those with moderate or severe illness should seek health care.

\section{Washing Hands with Soap and Water}

Washing hands with soap and water for 20 to 30 seconds whenever people touch potentially contaminated surfaces is an important method for the prevention of infection.

\section{Sanitizing Potentially Contaminated Surfaces}

All surfaces of furniture in public places that are touched by number of people should be adequately cleaned and sanitized to prevent spread of infection.
During the last 3 months, major efforts have been made to provide public health information on COVID-19 epidemic to the population and methods by which individuals can reduce risk of the getting infected through all media of communications. If the aware population follows all these steps, it will be possible to bring some reduction in the magnitude of infection over the next 12 months period.

\section{Current Status of the Epidemic in India}

The most striking aspects of the COVID-19 pandemic are the speed spread of infection; the most bewildering aspect is the reported variations in infection rates and health outcomes of the infection. The reported data on cases, cases/ million population, recoveries, and deaths in the world, some countries with high COVID-19 caseloads, and India are given in - Fig. 2 . There are large differences between countries in terms both of confirmed cases and deaths. India has the lowest caseload and deaths per million population. Available global data indicate that despite better equipped health care system and aware population accessing available facilities, morbidity and mortality rates in USA and European countries are higher as compared with the Indian scenario. To some extent, the lower morbidity and mortality in India could be due to lower testing of populations groups, incomplete reporting of test results, and under-reporting of cases and deaths. There have been worries that the COVID-19 has increased disparities in health care, ${ }^{28}$ lockdown has aggravated livelihood crisis, ${ }^{28}$ and lockdown may not prevent severe infections, ${ }^{29}$ especially in those with noncommunicable diseases. ${ }^{30}$ Recent publications from Europe and USA have shown that hospitalization of all infected patients (even the asymptomatic and mild cases) and aggressive respiratory interventions (including use of ventilators) in moderate and severe cases may not improve health outcomes; there is a possibility that such interventions may increase the severity by triggering inflammatory storm and might result in higher case fatality rates. ${ }^{24}$

-Fig. 3 depicts the epidemic curve showing the cumulative number of confirmed cases, active cases, recoveries, and deaths in India between January 30, 2020 to

\begin{tabular}{|c|c|c|c|c|c|c|}
\hline Country & \begin{tabular}{|c|} 
Confirmed \\
cases
\end{tabular} & Deaths & $\begin{array}{l}\text { Active } \\
\text { cases }\end{array}$ & \begin{tabular}{|c|} 
Cases/1000000 \\
inhabitants*
\end{tabular} & \begin{tabular}{|c|} 
Deaths $/ 1000000$ \\
inhabitants
\end{tabular} & $\begin{array}{c}\text { Mortality } \\
\text { rate }\end{array}$ \\
\hline World & $40,14,265$ & \begin{tabular}{|l|}
$2,70,740$ \\
\end{tabular} & $23,52,470$ & 515 & 35 & 7 \\
\hline USA & $13,22,154$ & 78,616 & $10,19,789$ & 3,994 & 238 & 6 \\
\hline Spain & $2,60,117$ & 26,299 & 65,410 & 5,563 & 562 & 10 \\
\hline Italy & $2,17,185$ & 30,201 & 87,961 & 3,592 & 500 & 14 \\
\hline UK & $2,11,364$ & 31,241 & $1,79,779$ & 3,114 & 460 & 15 \\
\hline Russia & $1,87,859$ & 1,723 & $1,59,528$ & 1,287 & 12 & 1 \\
\hline France & $1,76,079$ & 26,230 & 94,067 & 2,698 & 402 & 15 \\
\hline Germany & $1,70,588$ & 7,510 & 21,378 & 2,036 & 90 & 4 \\
\hline Brazil & $1,46,894$ & 10,017 & 77,580 & 691 & 47 & 7 \\
\hline Turkey & $1,35,569$ & 3,689 & 45,484 & 1,607 & 44 & 3 \\
\hline Iran & $1,04,691$ & 6,541 & 14,313 & 1,246 & 78 & 6 \\
\hline China & 82,887 & 4,633 & 208 & 58 & 3 & 6 \\
\hline Canada & 66,434 & 4,569 & 31,459 & 1,760 & 121 & 7 \\
\hline Peru & 61,847 & 1,714 & 41,121 & 1,876 & 52 & 3 \\
\hline India & 59,662 & 1,981 & 39,834 & 43 & 1 & $\underline{3}$ \\
\hline
\end{tabular}

Fig. 2 COVID-19 pandemic current status (as of May 9, 2020). 


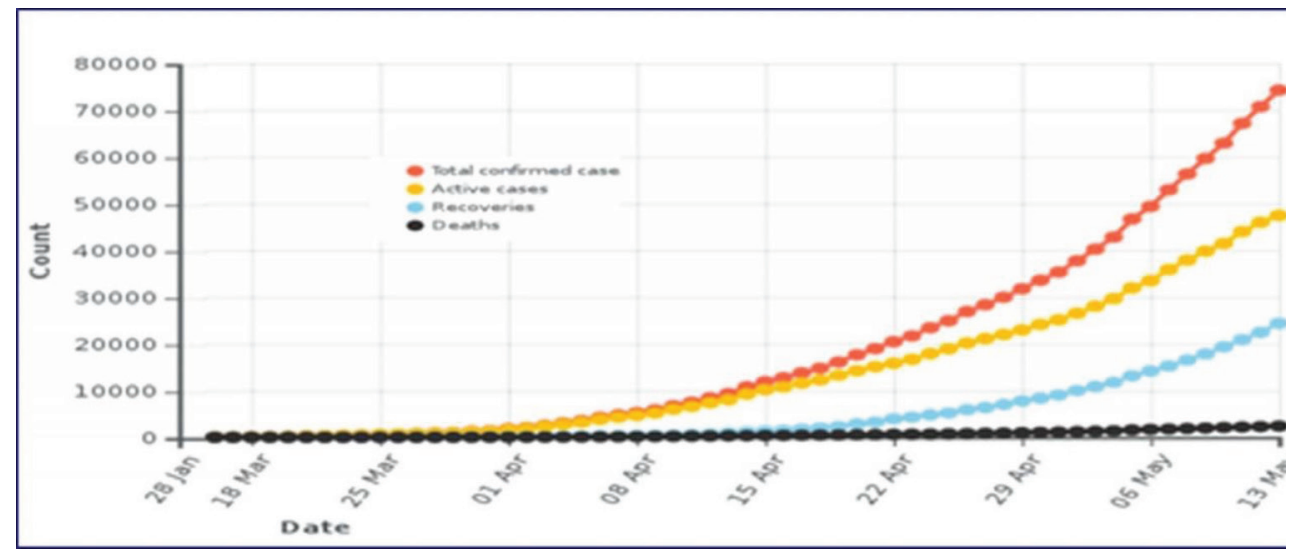

Fig. 3 COVID-19 epidemic curve in India.

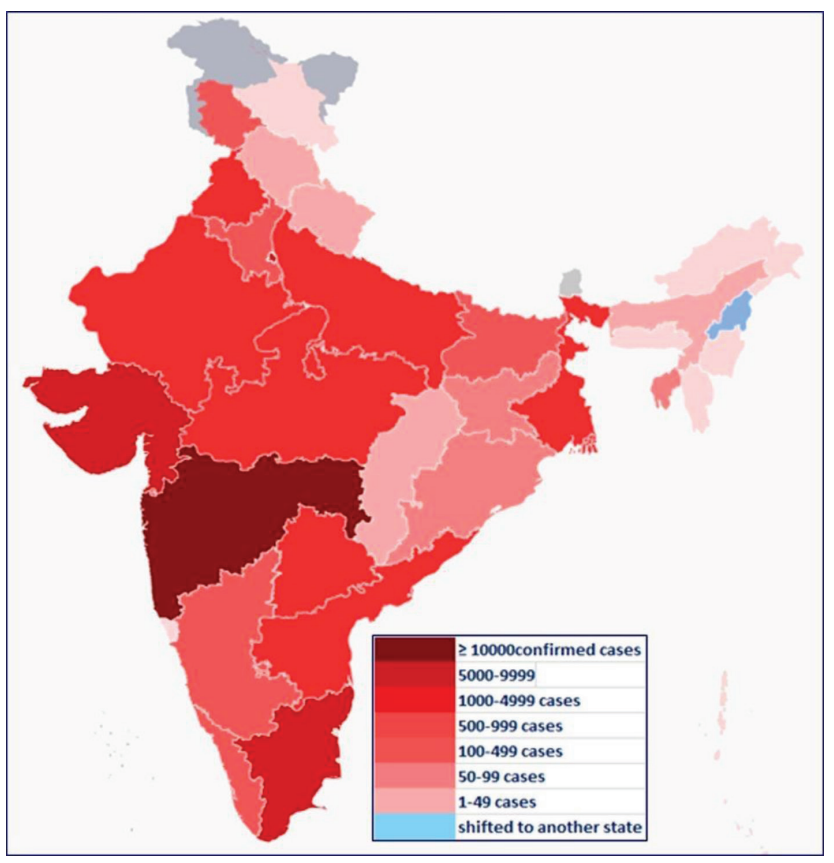

Fig. 4 Interstate differences in COVID-19 confirmed cases (as of May 10, 2020),

May $13,2020 .^{3}$ Over time there has been a linear increase in the number of confirmed cases. Part of the increase could be due to increased testing and reporting, identification of hot zones, and screening of the residents in these areas. State-wise distribution of confirmed cases and deaths is given in -Figs. $\mathbf{4}$ and 5. $^{3}$ Most of the confirmed cases, recovered cases, and deaths are from urban areas. The highest recovery rates and lowest fatality rates are reported from Kerala.

The country is moving toward progressive easing of the lockdown, so that economic employment activities resume, essential goods and services reach the population. At the district and below district level, three categories of zones (red, yellow, and green) have been identified based on the data on number of confirmed cases; ${ }^{31}$ people residing in green zones will be able to move around and get back to their work. Indians stranded abroad and the

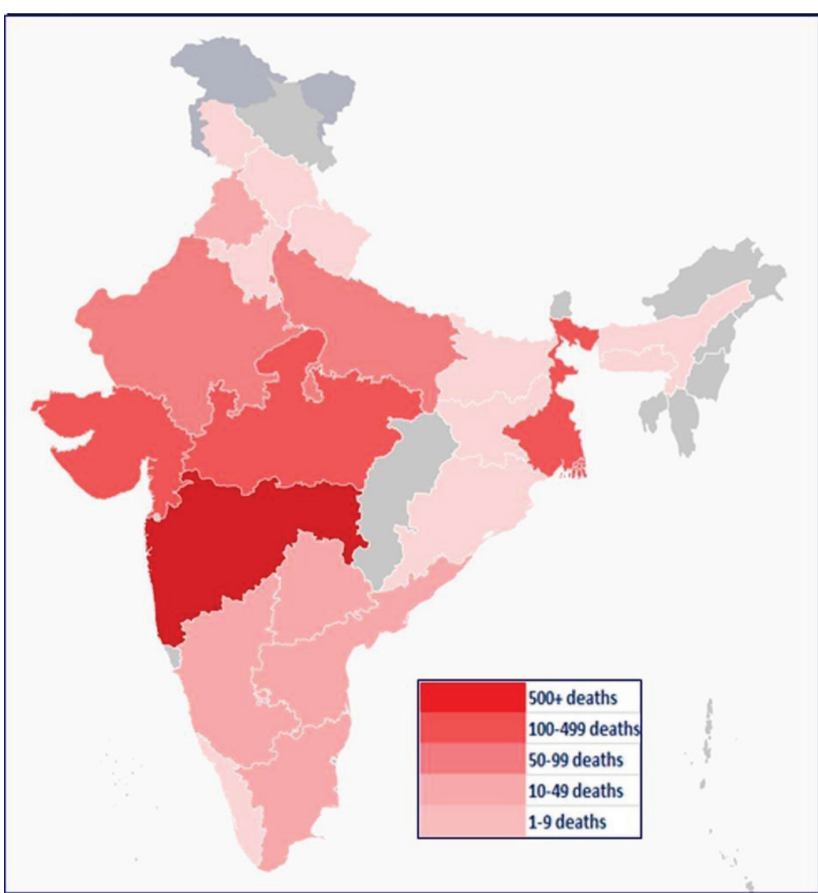

Fig. 5 Interstate differences in COVID-19 deaths (as of May 10, 2020)

migrants stranded in other states are returning home. Soon public transport is expected to open so that people can move from home to workplace. All these will inevitably lead to an increase in the number of infected patients, but the health system and the people are expected to be ready to cope with this.

\section{Health Systems Response to COVID-19 Epidemic in Kerala}

In India, Kerala was the first state to report COVID-19 cases and over the last 3 months the state health system has meticulously recorded and reported the evolution of the epidemic in Kerala. A review of these prospectively reported data can provide some insights and evidence based on the impact of effective implementation of the Indian guidelines for the management of COVID-19 epidemic. ${ }^{5}$ 
-Fig. 6 shows the number of COVID-19 cases (confirmed, active, recovered, and deaths) in Kerala from January 30, 2020 to May 5, 2020.

There was a progressive linear increase in confirmed and active cases between January 30, 2020 to April 7, 2020. All through April and first week of May:

- The cumulative number of confirmed cases continued to increase in a linear fashion with some flattening over time (impact of lockdown?).

- Number of recovered cases steadily increased.

- Number of active infections declined.

Keeping the family and contacts of the infected patients in isolation is an essential component of the epidemic control measures. Till May 10, 2020, a total of 20,157 people have been kept under observation. Of these 19,810 were kept under observation at home. Home isolation helps the infected person and family to cope with the anxieties associated with isolation in the comfort of their homes with their family's support. It is relatively easy to improve compliance with isolation under these circumstances; this in turn has a major impact on preventing COVID-19 spread. So far only 347 people required hospitalization. In Kerala, designated quarantine facilities and designated hospital beds at various levels for COVID-19 have remained fully functional but majority of these remained under-utilized. The fear that the epidemic will overwhelm the health system was shown to be unwarranted.

As of May 10, 2020 there were 505 total confirmed cases in Kerala; of these 485 (96\%) had recovered and only 17 cases (3.4\%) are active. There were three deaths one each in the districts of Thiruvananthapuram, Malappuram, and Ernakulam (case fatality rate of $0.6 \%$ ). Globally and within India, Kerala has the highest rate for recovered cases and lowest case fatality rates. The state implemented the national guidelines of:

- Home-based isolation and care for infected person (both asymptomatic and those with mild infection).
- Home isolation and care for the families and contact of infected patients.

- Home follow-up of infected patients by primary health care personnel.

- Referral of only those with moderate and severe symptoms to hospital for intensive care.

- Optimal use of the available tertiary health care facilities to provide care for the severely affected patients and those with comorbidities.

This approach:

- Provided needed comfort and care and minimized psychosocial trauma of the infected patients and their families.

- Resulted in high recovery rates, low infection rates, low hospitalization rates, and low case fatality rates.

- Minimized the adverse impact of COVID-19 on other health care programs and management of people with other illnesses.

- Will be sustainable through the expected continued linear increase in COVID cases over the next few months and some upsurge during winter.

\section{Way Forward}

Containment and control of rapidly spreading airborne droplet infections like COVID-19 is difficult. India responded to COVID-19 pandemic with commendable speed by drawing up the National Containment Plan for COVID-19. The plan envisaged community and primary health care-centered approach to screening, containment, and care during COVID-19 epidemic.

Ban on international travel and pre-emptive lockdown flattened the epidemic curve in the initial months. During the lockdown phase, the health system has been reorganized so that it can provide the needed care for increasing number of COVID-19 patients at all levels of health care

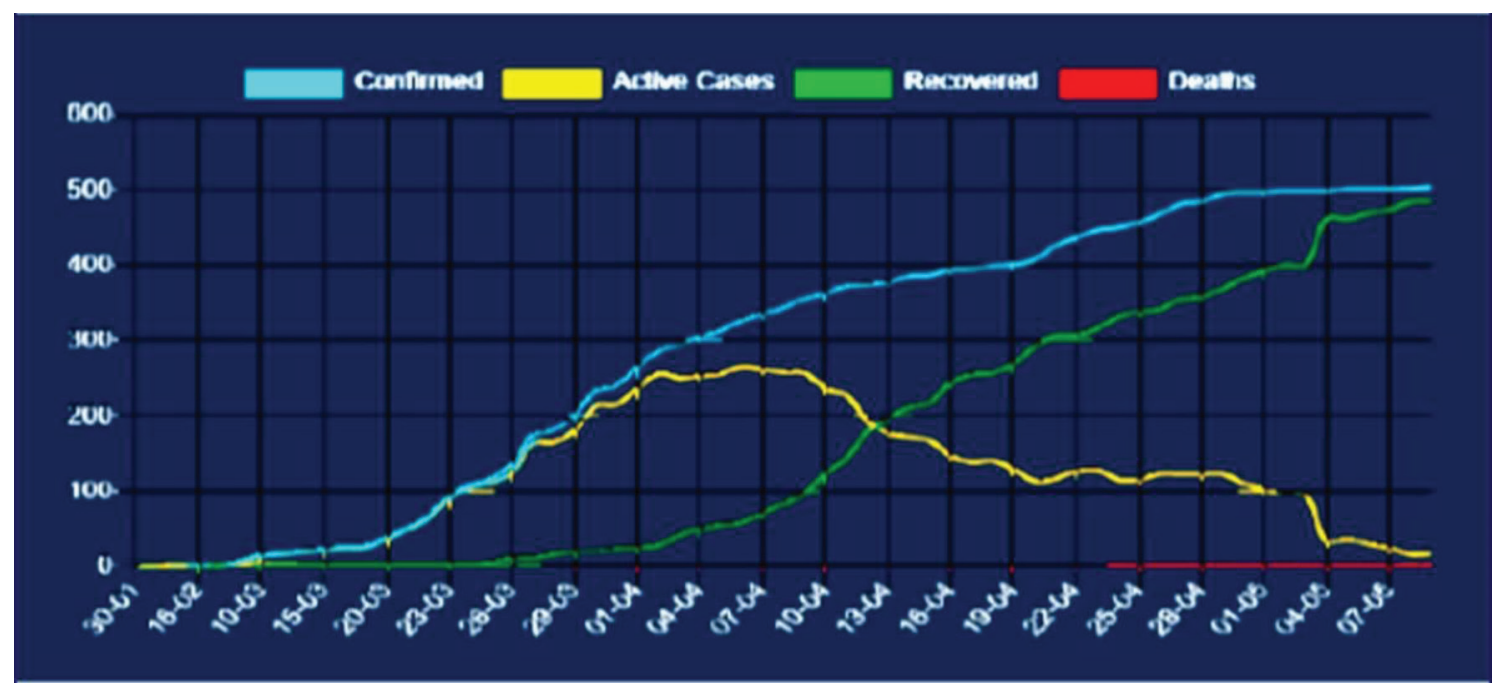

Fig. 6 Summary of COVID-19 cases in Kerala (as of May 10, 2020). 
ranging from home-based care to tertiary care institutions. Guidelines for providing needed care for patients with varying severity of infection have been revised taking the experience of last 3 months; ${ }^{32-34}$ health care providers have gained experience and can cope with increased number of COVID-19 patients in the coming months.

Simultaneously, every effort has been made to inform the public about the epidemic and the precautions that everyone has to take such as physical distancing, wearing of masks, hand washing after touching surfaces in public spaces, and avoiding congregations (education, entertainment, social, religious) to minimize the risk of infection. It is expected that the aware population will take the precautions and ensure that the number of cases is kept at a relatively low level. Global comparison shows that India has low infection rates, high recovery rates, and low fatality rates.

In the coming months, the people and health system will have to evolve a sustainable strategy to provide needed care for COVID-19 cases and minimize the adverse impact of COVID-19 on other health care programs and management of patients with other illnesses. The process of transition will have to continue until such time that the management of the new infection is implemented as a part of the ongoing health programs and other health programs, care of patients with other illnesses and elective intervention procedure, are restored fully.

\section{Conflict of Interest}

None declared.

\section{References}

1 WHO. Coronavirus Disease (COVID-2019) Situation Reports. Availableat:https://www.who.int/emergencies/diseases/novelcoronavirus-2019/situation-reports. Accessed May 15, 2020

2 MoHFW. Containment Plan for Novel Coronavirus Disease 2019 (COVID 19). Available at: https://ncdc.gov.in/showfile. php?lid=528. Accessed May 15, 2020

3 MoHFW. COVID-19 India. Available at: https://www.mohfw. gov.in/.in/covid-19/. Accessed May 15, 2020

4 WHO. International Health Regulations. Available at: https:// www.who.int/ihr/publications/9789241580496/en/. Accessed May 15, 2020

5 GOK. Official Kerala COVID-19 Statistics. Available at: https:// dashboard.kerala.gov.in/. Accessed May 15, 2020

6 MoHFW. Guidelines for Quarantine Facilities COVID-19. Availableat: https://ncdc.gov.in/showfile.php?lid=504. Accessed May 15, 2020

7 MoHFW. Guidelines for home quarantine. Available at: https:// www.mohfw.gov.in/pdf/Guidelinesforhomequarantine.pdf. Accessed May 15, 2020

8 MoHFW. Revised Guidelines for Quarantine Facilities COVID-19. Availableat:https://ncdc.gov.in/showfile.php?lid=552.Accessed May 15, 2020

9 MoHFW.AdditionalGuidelinesforQuarantineof Returneesfrom Abroad/Contacts/Isolation of Suspect or Confirmed Cases in Private Facilities. Available at: https://www.mohfw.gov.in/pdf/ Additionalguidelinesforquarantineofreturneesfromabroadc ontactsisolationofsuspectorconfirmedcaseinprivatefacilities. pdf. Accessed May 15, 2020
10 MoHFW.COVID-19:Railway Coaches.Availableat:https://www. mohfw.gov.in/pdf/GuidanceDocumentonappropriatemanagementofsuspectconfirmedcasesofCOVID19RailwayCoaches COVIDCareCenters.pdf. Accessed May 15, 2020

11 MoHFW. Lockdown. Available at: https://www.mohfw.gov.in/ pdf/Annexure_MHA.pdf. Accessed May 15, 2020

12 ICMR Revised Strategy of COVID19 Testing in India. Available at: https://www.icmr.gov.in/cteststrat.html. Accessed May 15, 2020

13 ICMR Guidelines for COVID19 Testing in Private Laboratories. Availableat: https://www.mohfw.gov.in/pdf/NotificationofICM Rguidelines for COVID 19 testinginpriva telaboratoriesi India. pdf. Accessed May 15, 2020

14 ICMR Sentinel Surveillance to Detect Community Transmission of COVID-19. Available at: https://www.icmr.gov.in/cteststrat. htm. Accessed May 15, 2020

15 MoHFW. District level Facility Based Surveillance for COVID-19 https://www.mohfw.gov.in/pdf/DistrictlevelFacilitybased surveillanceforCOVID19.pdf. Accessed May 15, 2020

16 MoHFW. Guidelines for Home Based Care of 2019-nCoV Novel Corona Virus (2019-nCoV). Available at: https://ncdc.gov.in/ showfile.php?lid=462. Accessed May 15, 2020

17 MoHFW. Guidelines on Clinical Management of Severe Acute Respiratory Illness (SARI) in Suspect/Confirmed Novel Coronavirus (nCoV) Cases. Available at: https://ncdc.gov.in/ showfile.php?lid=458. Accessed May 15, 2020

18 MoHFW. Guidelines for Screening Centres. Available at: https://ncdc.gov.in/showfile.php?lid=452. Accessed May 15, 2020

19 MoHFW. Guidelines for Elderly and High Risk Groups to Safeguard from COVID- 19 Outbreak. Available at: https:// ncdc.gov.in/showfile.php?lid=526. Accessed May 15, 2020

20 MoHFW. COVID 19 Guidelines for Setting Up Isolation Facility/ Ward. Available at: https://ncdc.gov.in/showfile.php?lid=503. Accessed May 15, 2020

21 MoHFW. Discharge Policy of 2019-n CoV Case. Available at: https://ncdc.gov.in/showfile.php?lid=505. Accessed May 15, 2020

22 Guidelines for handling, treatment and disposal of waste generated during treatment/diagnosis/quarantine of COVID-19 patients. Available at: https://ncdc.gov.in/showfile.php?lid=551. Accessed May 15, 2020

23 MoHFW. Enabling Delivery of Essential Health Services during the COVID 19 Outbreak: Guidance Note. Available at: https:// www.mohfw.gov.in/pdf/EssentialservicesduringCOVID19. Accessed May 15, 2020

24 Anesi GL Coronavirus disease. (COVID-19): Critical Care and Airway Management Issues. Available at: https://www.uptodate.com/contents/coronavirus-disease-2019-covid-19-critical-care-and-airway-management-issues. Accessed May 15, 2020

25 MoHFW. Protective Measures against Corona Virus. Available at: https://www.mohfw.gov.in/pdf/ProtectivemeasuresEng.pdf. Accessed May 15, 2020

26 Office of Principal Scientific Advisor to GoI Homemade Masks to Overcome Shortage. Available at: https://pib.gov.in/ newsite/PrintRelease.aspx?relid=200916. Accessed May 15, 2020

27 Office of Principal Scientific Advisor to GoI Masks for Curbing the Spread of SARS-CoV-2 Coronavirus. Available at: http:// bit.ly/DIYMasksCorona. Accessed May 15, 2020

28 Cash R, Patel V. Has COVID-19 Subverted Global Health? The Lancet 2020. Doi: 10.1016/S0140-6736(20)31089-8

29 Giesecke J. The Invisible Pandemic. The Lancet 2020. Doi:10.1016/S0140-6736(20)31035-7 
30 Kluge HHP, Wickramasinghe K, Rippin HL, et al. Prevention and Control of Non-communicable Diseases in the COVID-19 Response. Lancet 2020. Doi: 10.1016/S0140-6736(20)31067-9

31 MoHFW. Micro Plan for Containing Local Transmission of Coronavirus Disease (COVID-19). Available at: https://ncdc. gov.in/showfile.php?lid=529. Accessed May 15, 2020

32 MoHFW. Revised Guidelines for Home Isolation of Very Mild/ pre-symptomatic COVID-19 Cases. Available at: https://www. mohfw.gov.in/pdf/RevisedguidelinesforHomeIsolation ofverymildpresymptomaticCOVID19cases10May2020.pdf. Accessed May 15, 2020
33 MoHFW. Revised Discharge Policy for COVID-19. Available at: https://www.mohfw.gov.in/pdf/ReviseddischargePolicyfor COVID19.pdf. Accessed May 15, 2020

34 MoHFW. Guidance Document on Appropriate Management of Suspect/Confirmed Cases of COVID19. Available at: https:// www.mohfw.gov.in/pdf/GuidanceDocumentonappropriate managementofsuspectconfirmedcases of COVID19. Accessed May 15, 2020 